University of Nebraska - Lincoln

DigitalCommons@University of Nebraska - Lincoln

Faculty Publications, Department of Psychology

Psychology, Department of

8-2003

\title{
The Teenage Inventory of Social Skills: Reliability and Validity of the Spanish Translation
}

\author{
Cándido J. Inglés \\ Universidad de Murcia, Spain, jingles@um.es \\ María D. Hidalgo \\ Universidad de Murcia, Spain \\ F. Xavier Méndez \\ Universidad de Murcia, Spain \\ Heidi M. Inderbitzen \\ University of Nebraska-Lincoln
}

Follow this and additional works at: https://digitalcommons.unl.edu/psychfacpub

Part of the Psychiatry and Psychology Commons

Inglés, Cándido J.; Hidalgo, María D.; Méndez, F. Xavier; and Inderbitzen, Heidi M., "The Teenage Inventory of Social Skills: Reliability and Validity of the Spanish Translation" (2003). Faculty Publications,

Department of Psychology. 505.

https://digitalcommons.unl.edu/psychfacpub/505

This Article is brought to you for free and open access by the Psychology, Department of at DigitalCommons@University of Nebraska - Lincoln. It has been accepted for inclusion in Faculty Publications, Department of Psychology by an authorized administrator of DigitalCommons@University of Nebraska - Lincoln. 
Published in Journal of Adolescence 26:4 (August 2003), pp. 505-510; doi: 10.1016/S0140-1971(03)00032-0

Copyright (c) 2003 The Association for Professionals in Services for Adolescents.

Published by Elsevier Science Ltd. Used by permission.

Submitted January 7, 2003; accepted January 20, 2003; published online July 5, 2003.

\title{
The Teenage Inventory of Social Skills: Reliability and Validity of the Spanish Translation
}

\author{
Cándido J. Inglés, ${ }^{1}$ María D. Hidalgo, ${ }^{1}$ \\ F. Xavier Méndez, ${ }^{1}$ and Heidi M. Inderbitzen ${ }^{2}$ \\ 1. Departamento de Personalidad Evaluacion y Tratamiento Psicologicos, \\ Facultad de Psicologia, Universidad de Murcia, Murcia 30008, Spain \\ 2. University of Nebraska-Lincoln, Lincoln, Nebraska, USA \\ Corresponding author - C. J. Inglés, tel 34 68-36-39-75, fax 34 68-36-41-15, email jingles@um.es
}

\section{Introduction}

Peer relationships play a critical role in the development of social skills and personal feelings essential for personal growth and life-long adjustment (Hansen, Nangle, \& Meyer, 1998), and are a key factor in the development of personal identity and independence from the family circle (Mayseless, Wiseman, \& Hai, 1998).

Children and adolescents who are popular or accepted by their peers receive more social reinforcement, which improves their adaptation, not only in social areas but also in personal and school ones (Inderbitzen, Walters, \& Bukowski, 1997; La Greca \& Lopez, 1998). Acceptance or popularity among peers is closely connected to prosocial behavior (Markiewicz, Doyle, \& Brendgen, 2001).

The Teenage Inventory of Social Skills (TISS; Inderbitzen, 1992) is the only self-report designed exclusively to reflect behaviors functionally related to peer acceptance in adolescence. The psychometric properties of the TISS have proved to be satisfactory in samples of adolescents in USA (Inderbitzen, 1992; Inderbitzen \& Foster, 1992; Inderbitzen \& Garbin, 1992), but they have not been examined among those who are Spanish-speaking. The aim of the present work was to determine the reliability and validity of the Spanish translation of the TISS. 


\section{Study 1: Factor Structure, Internal Consistency and Descriptive Study}

\subsection{Method}

\subsubsection{Subjects}

The initial sample consisted of 692 participants. Of this total, $32(4.62 \%)$ were excluded from the study because their answers were incomplete $(n=23 ; 3.32 \%)$ or their parents did not give their informed written consent for them to participate $(n=9 ; 1.30 \%)$. All the children participated voluntarily. The final sample was made up of 660 students (396 boys and 264 girls) from Grades 6-11, randomly selected from public and private schools in Murcia (Spain). Ages ranged from 12 to 17 $(M=14.28$; S.D. $=1.64)$. Because of the racial and ethnic homogeneity of the county, the majority of students were Caucasian (99\%). They did, however, represent a wide range of socioeconomic levels.

\subsubsection{Measure}

The TISS (Inderbitzen, 1992) assesses adolescent social competence as it relates to peer relationships. It comprises 40 items grouped into two scales, Prosocial Behavior and Asocial Behavior.

The TISS was translated into Spanish using a back translation method.

\subsubsection{Procedure}

The TISS was answered collectively in the classroom in groups of about 25 children. The researchers pointed out to the children that their participation was strictly voluntary. The copies were given out together with instructions and the answer sheets, which would later be corrected by computer.

\subsection{Results}

\subsubsection{Confirmatory factor analysis}

Confirmatory factor analysis was conducted on the items of the TISS to confirm the two-factor structure presented by Inderbitzen (1992). Three fit indexes were used to evaluate the adequacy of the model tested: (1) square root mean residual (S-RMR), (2) goodness-of-fit index (GFI), and (3) adjusted goodness-of-fit index (AGFI). The results indicated that the two-factor model fit the data, with an S-RMR $=0.07$, a GFI $=0.88$, and an AGFI $=0.86$. The product-moment correlation of the two factors was -0.11 .

\subsubsection{Reliability}

The Cronbach's alpha internal consistency coefficients were 0.89 for the Prosocial Behavior and 0.84 for the Asocial Behavior scales.

\subsubsection{Gender and age differences in prosocial behavior and asocial behavior}

Girls $(M=94.64)$ scored higher in prosocial behavior than boys $(M=82.92), F(1,648)=111.51, p$ $=0.001$. The difference magnitude was large $(d=0.86)$, since it was greater than 0.80 , the value suggested by Cohen (1988) as being the lower limit of a high effect size. Boys $(M=55.16)$ scored higher than girls $(M=46.23)$ in asocial behavior, $F(1,648)=51.46, p=0.000$, with a medium effect size $(d=$ 
Table 1. Mean scores and standard deviations by gender for the two factors in Spain and USA

\begin{tabular}{|c|c|c|c|c|c|c|}
\hline & \multicolumn{2}{|c|}{ Males } & \multicolumn{2}{|c|}{ Females } & \multicolumn{2}{|c|}{ Males + females } \\
\hline & Spain & USA & Spain & USA & Spain & USA \\
\hline \multicolumn{7}{|l|}{ Prosocial behavior } \\
\hline Mean & 82.92 & 74.97 & 94.64 & 93.24 & 87.78 & 84.15 \\
\hline Standard deviation & 15.33 & 14.53 & 12.25 & 11.35 & 15.22 & 15.91 \\
\hline \multicolumn{7}{|l|}{ Asocial behavior } \\
\hline Mean & 55.16 & 55.35 & 46.23 & 44.97 & 51.45 & 50.16 \\
\hline Standard deviation & 13.95 & 12.12 & 11.30 & 10.84 & 13.60 & 12.61 \\
\hline
\end{tabular}

0.58). There were no statistically significant differences with regard to age or gender by age interactions. In Table 1, the means and standard deviations for both scales obtained with Grade 9 adolescents in this study and those in a study conducted by Inderbitzen (1992) are compared. Analysis of these data reveal a similar pattern, since in both countries: (a) girls display higher levels of prosocial behavior, (b) boys display higher levels of asocial behavior, and (c) both genders display higher levels of prosocial behavior than asocial behavior in their peer relationships. However, Spanish adolescents scored significantly higher in prosocial behavior, $t(1197)=2.25 ; p=0.05)$, due to the higher score for boys, $t(604)=4.06 ; p=0.001)$.

\section{Study 2: Convergent Validity}

\subsection{Method}

\subsubsection{Subjects}

The initial sample consisted of 533 participants, 17 (3.19\%) of whom were excluded from the study because of omissions and errors in their answers $(n=11 ; 2.06 \%)$, because their parents did not give informed consent for them to take part in the research $(n=4 ; 0.75 \%)$ or because they failed to reach a satisfactory level on the Eysenck Personality Questionnaire Sincerity scale $(n=2 ; 0.37 \%)$. All the students took part on a voluntary basis. Thus, the final sample was made up of 516 students (313 boys and 203 girls) from Grades 6-11, randomly selected from public and private schools in Murcia (Spain). Ages ranged from 12 to $17(M=14.29$; S.D. = 1.62). The majority of students were Caucasian $(99 \%)$.

\subsubsection{Instruments}

In addition to the TISS, the subjects also filled in the Matson Evaluation of Social Skills with Youngsters (MESSY; Matson, Rotatori, \& Helsel, 1983), the Assertive Scale for Adolescents (ASA; Lee, Hallberg, Slemon, \& Haase, 1985), the Assertiveness Scale (AS; Godoy, Gavino, Martorell, \& Silva, 1993), 
Table 2. Correlation with other social behavior self-reports

\begin{tabular}{|c|c|c|c|c|c|c|c|c|c|}
\hline \multirow[t]{2}{*}{ TISS } & \multirow{2}{*}{$\begin{array}{c}\text { ASA } \\
\text { AS }\end{array}$} & \multicolumn{5}{|c|}{ MESSY } & \multicolumn{3}{|l|}{ AS } \\
\hline & & AA & SA & $\mathrm{CH}$ & LS & Total & AS & AG & $\mathrm{SU}$ \\
\hline Prosocial behavior & 0.31 & -0.22 & 0.72 & $-0.05^{b}$ & -0.35 & -0.58 & 0.35 & -0.32 & $-0.03^{b}$ \\
\hline Asocial behavior & -0.20 & 0.72 & $-0.04^{b}$ & 0.52 & $0.11^{\mathrm{a}}$ & 0.54 & -0.27 & 0.48 & -0.32 \\
\hline
\end{tabular}

The correlations are significant at $p<0.001$, except where designated with "a", which are significant at $p<0.01$, and where designated with " $\mathrm{b}$ ", which are not significant. ASA = Assertive Scale for Adolescents (AS = assertiveness score). MESSY = Matson Evaluation of Social Skills with Youngsters (AA = Agressiveness $/$ antisocial behavior subscale; $\mathrm{SA}$ = social skills/assertiveness subscale; $\mathrm{CH}=$ conceit/haughtiness subscale; $\mathrm{LS}=$ loneliness/social anxiety subscale; Total $=$ MESSY total score). AS = assertiveness scale (AS = assertiveness subscale; AG = aggressiveness subscale; $\mathrm{SU}=$ submissiveness subscale).

and the Eysenck Personality Questionnaire (EPQ; Eysenck \& Eysenck, 1975), in order to study the TISS' convergent validity.

\subsubsection{Procedure}

To avoid tiring the subjects, the self-reports were applied in two sessions during the same week. The order of presentation of the scales was established at random for each group of students.

\subsection{Results}

\subsubsection{Correlation with other social behavior self-reports}

Table 2 shows the Pearson correlation coefficients among the TISS, the ASA, the MESSY, and the AS. Prosocial behavior correlated positively with social skills and assertiveness and negatively with social inappropriateness, loneliness and social anxiety, aggressiveness and antisocial behavior. Asocial behavior correlated positively with aggressiveness and antisocial behavior, social inappropriateness (Total MESSY), conceit and haughtiness.

\subsubsection{Correlation with personality variables}

Adolescents who reported higher levels of prosocial behavior scored higher in extraversion $(r=$ $0.12 ; p=0.01)$ and lower in psychoticism $(r=-0.37 ; p=0.000)$. Prosocial behavior was not correlated with neuroticism $(r=0.06 ; p=0.204)$. Additionally, adolescents who reported higher levels of asocial behavior scored higher in psychoticism $(r=0.44 ; p=0.000)$. Asocial behavior was not correlated with neuroticism $(r=0.07 ; p=0.101)$ and extraversion $(r=0.08 ; p=0.072)$.

\section{Discussion}

The main aim of this research was to examine the psychometric properties of the Spanish translation of the TISS. Confirmatory factor analysis supported the two-factor structure founded by Inderbitzen and Garben (1992). The relation between the two factors was similar to the one found by Inder- 
bitzen and Foster (1992), reflecting, in both cases, that low scores in prosocial behavior are associated with high scores in asocial behavior.

Acceptable levels of internal consistency were obtained for the TISS scale scores, which were similar to those obtained by Inderbitzen and Foster (1992).

The relationship between the TISS and other measures supports its construct validity. As expected, prosocial behavior related positively to social skills and assertiveness, and negatively to social inappropriateness, loneliness and social anxiety, aggressiveness and antisocial behavior. The opposite pattern was seen with asocial behavior, which related positively to aggressiveness and antisocial behavior, social inappropriateness, conceit and haughtiness, loneliness and social anxiety, and negatively with submissiveness and assertiveness. Sociometric studies (Inderbitzen, Walters, \& Bukowski, 1997; La Greca \& Lopez, 1998), and the research with adolescents using self-reports point in the same direction (La Greca \& Lopez, 1998).

Additionally, the construct validity of the TISS was supported by the relationship with personality variables. Adolescents who scored low in psychoticism and high in extraversion reported a higher level of prosocial behavior. The positive correlation of asocial behavior with psychoticism is congruent with the description of this variable (Eysenck \& Eysenck, 1975). Furnham and Gunter (1983) found that adolescents with high psychoticism scores tend to report social difficulties.

Females report higher levels of prosocial behavior in peer relationships, whereas males report higher levels of asocial behavior. These results coincide with those obtained by Inderbitzen (1992) with American adolescents, and can be explained by the fact that females stress the importance of prosocial behavior (e.g. helping, sharing, loyalty and emotional support) in peer relationships more than males do (Asher \& Parker, 1989).

This study presents some limitations that further research should remedy: selection of general and clinical samples of Spanish-speaking adolescents from other countries (USA, Mexico, Puerto Rico, etc.) to enable a generalization of the results, comparison with other assessment procedures (observation, reports from significant people, etc.) and calculation of the inventory's temporal stability. Additionally, the sensitivity of the questionnaire requires consideration in terms of ability to detect improvement in social functioning resulting from treatment programs. In spite of these limitations, overall results support use of the Spanish translation of the TISS.

\section{References}

Asher \& Parker (1989) $\varangle$ S. R. Asher and J. G. Parker, Significance of peer relationship problems in childhood. In: B. H. Schneider, G. Attili, J. Nadel, and R. P. Weissberg, Editors, Social competence in developmental perspective, Kluwer Academic Press, Boston (1989), pp. 5-23.

Cohen (1988) 4 J. Cohen. Statistical power analysis for the behavioral sciences (2nd ed.), Erlbaum, Hillsdale, NJ (1988).

Eysenck \& Eysenck (1975) 4 H. J. Eysenck and S. B. G. Eysenck. Manual of the Eysenck Personality Questionnaire, Hodder and Stoughton, London (1975).

Furnham and Gunter (1983) 4 A. Furnham and B. Gunter, Sex and personality differences in self-reported social skills among British adolescents. Journal of Adolescence 6 (1983), pp. 57-69.

Godoy, Gavino, Martorell, \& Silva (1993) 4 A. Godoy, A. Gavino, M. C. Martorell, and F. Silva, Assertiveness Scale for children and adolescents. In: M. Forns and M. T. Anguera, Editors, Recent contributions to psychological assessment, PPU, Barcelona (1993), pp. 247-264. 
Hansen, Nangle \& Meyer (1998) — D. J. Hansen, D. W. Nangle, and K. A. Meyer, Enhancing the effectiveness of social skills interventions with adolescents. Education and Treatment of Children 21 (1998), pp. 489-513.

Inderbitzen (1992) 4 H. M. Inderbitzen, Exploration of factor structure and gender differences on the TISS. Unpublished manuscript, University of Nebraska-Lincoln (1992).

Inderbitzen \& Foster (1992) 4 H. M. Inderbitzen and S. L. Foster, The Teenage Inventory of Social Skills: Development, reliability, and validity. Psychological Assessment 4 (1992), pp. 451-459.

Inderbitzen \& Garbin (1992) 4 H. M. Inderbitzen and C. P. Garbin An investigation of the construct validity of the Teenage Inventory of Social Skills: A convergent multivariate approach. Paper presented at the annual meeting of the Association for the Advancement of Behavior Therapy. Boston, MA (1992).

Inderbitzen, Walters, \& Bukowski (1997) 4 H. M. Inderbitzen, K. S. Walters, and A. L. Bukowski, The role of social anxiety in adolescent peer relations: Differences among sociometric status groups and rejected subgroups. Journal of Clinical Child Psychology 26 (1997), pp. 338-348.

La Greca \& Lopez (1998) 4 A. M. La Greca and N. Lopez, Social anxiety among adolescents: Linkages with peer relations and friendships. Journal of Abnormal Child Psychology 26 (1998), pp. 83-94.

Lee, Hallberg, Slemon, \& Haase (1985) 4 D. Y. Lee, E. T. Hallberg, A. G. Slemon, and R. F. Haase, An assertiveness scale for adolescents. Journal of Clinical Psychology 41 (1985), pp. 51-57.

Markiewicz, Doyle, \& Brendgen (2001) \ D. Markiewicz, A. B. Doyle, and M. Brendgen, The quality of adolescents' friendships: Associations with mothers' interpersonal relationships, attachments to parents and friends, and prosocial behaviors. Journal of Adolescence 24 (2001), pp. 429-445.

Matson, Rotatori, \& Helsel (1983) ४ J. L. Matson, A. F. Rotatori, and W. J. Helsel, Development of a rating scale to measure social skills in children: The Matson Evaluation of Social Skills with Youngsters (MESSY). Behavior Research and Therapy 21 (1983), pp. 335-340.

Mayseless, Wiseman, \& Hai (1998) \ O. Mayseless, H. Wiseman, and I. Hai, Adolescents' relationships with father, mother, and same-gender friend. Journal of Adolescent Research 13 (1998), pp. 101-123. 